\title{
Summary of the International Workshop: National Laws and Guidelines for Control of Infections
}

\section{Participants:}

Dr. Bertil Nyström

Karolinska Institute

Department of Clinical Microbiology

Huddinge University Hospital

Huddinge, Sweden

Professor Dr. Hans Reber

Central Laboratory, Kantonspital

Basel, Switzerland

\author{
Professor Dr. Wolfgang Weuffen \\ Hygiene Institute \\ Greifswald, German Democratic Republic \\ Moderator: \\ Dr. William Schaffner \\ Department of Preventive Medicine \\ Vanderbilt University School of Medicine \\ Nashville, Tennessee, USA
}

By way of introduction, Dr. Nyström described the hospital system in Sweden which is organized in a pyramidal fashion within each county. The largest hospital in each county contains a Department of Clinical Microbiology and the organization of hospital infection control activities follows this county structure.

An infection control unit is located within the clinical microbiology laboratory of the major county hospital. The head of the unit, the hospital epidemiologist, is usually a specialist in clinical microbiology with medical training. The epidemiologist has an infection control committee consisting of clinicians of various specialties, especially surgeons. There are usually two infection control nurses per county (now approximately 1 nurse/3000 beds with an eventual goal of 1 nurse/1000 to 1500 beds). The nurses advise the ward staff in all the county hospitals. There are only some 50 infection control nurses in Sweden; financial restrictions curtail the development of infection control activities.

The scarcity of infection control nurses requires that surveillance schemes rely primarily on laboratory data. However, wound infection surveillance systems are run by local staff in several surgical departments.

The only law relating to hospital infection control concerns the use of sterile disposable materials. The National Board of Health and Welfare first published guidelines in 1959 and its third edition appeared in 1980 . Local committees may adapt these guidelines for their own county procedure manuals.
The organization of hospital infection control in Denmark and Norway follows a similar pattern. The Scandinavian countries have a strong preference for guidelines rather than laws.

Professor Reber picked up this theme, emphasizing the flexibility of guidelines, their adaptation to local circumstances, and, compared with laws, the ease with which guidelines can be changed. In Switzerland, the Kanton (county) public health physician's responsibility includes infection control. There are no official governmental laws or guidelines, but numerous professional associations have offered expert advisories on various infection control issues. This system preserves flexibility and local initiatives.

Professor Weuffen reported that representatives from eight socialist countries had met in 1979 and agreed upon 22 "theses" or goals for hospital hygiene. Among others, these included the following: 1) a full-time hospital epidemiologist for hospitals of over 600 beds, 2) an endorsement of surveillance, 3 ) cooperation with regional public health officers, 4) support for a future requirement that medical device manufacturers must provide a certificate which describes how the device is to be decontaminated, and 5) support for research in hospital infection control.

In contrast to the previous two countries, the German Democratic Republic has a broad law which refers to many aspects of infection control, including communicable disease reporting, patient isolation, and sterilization and disinfection practices. 


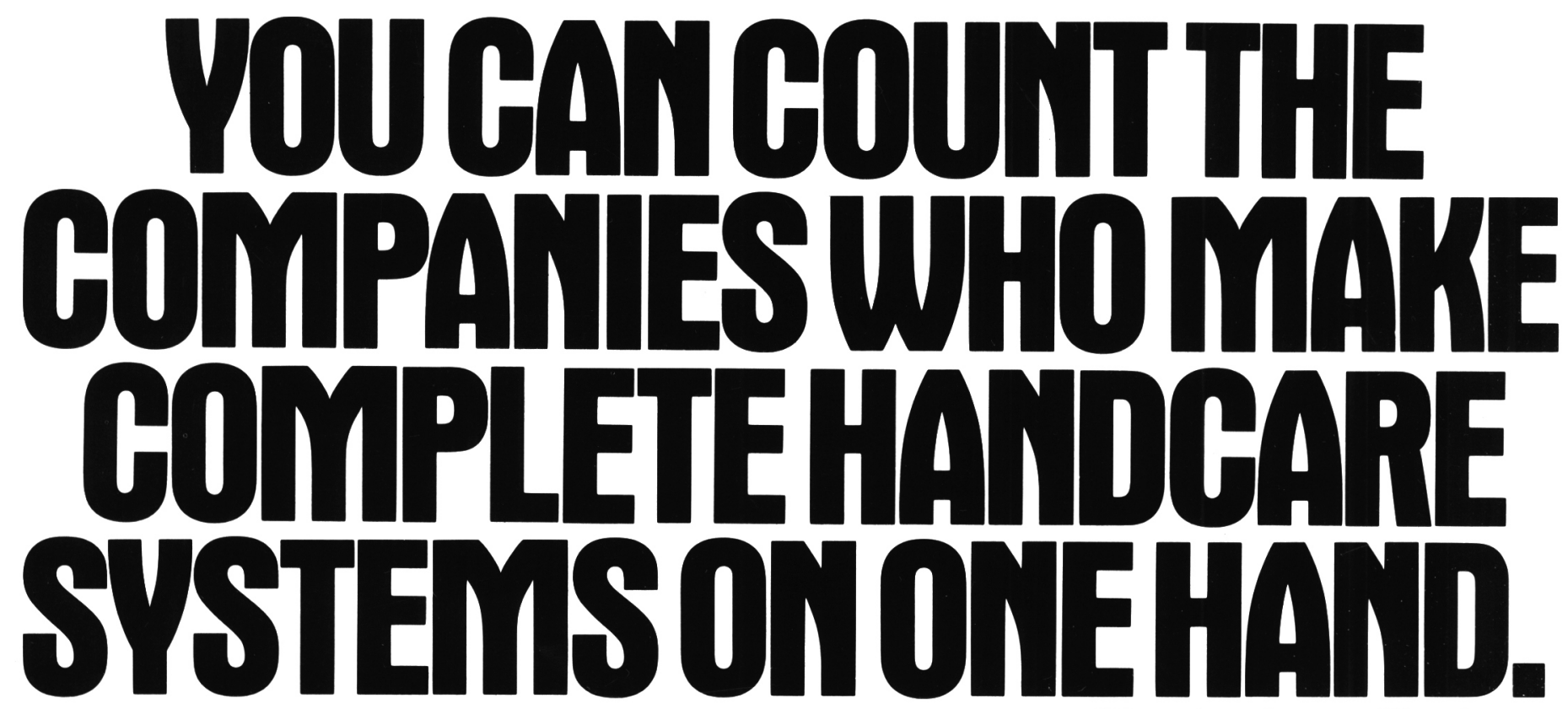

There's only one. Huntington Laboratories, developers of The Care System. ${ }^{\text {TM }}$ At Huntington, we believe complete handcare starts with a complete line of superior products. Effective cleaners like Wash, ${ }^{\circledR}$ Germa-Care, ${ }^{\circledR}$ Germa-Medica "MG", SanaScrub, ${ }^{\circledR}$ and OR/Scrub ${ }^{\circledR}$.And for after washing, Bacti-Care ${ }^{\circledR}$ a non-petroleum based hand lotion. (It doesn't promote bacterial growth like other lotions do.)

The Care System helps you meet C.D.C. Guidelines while preventing the spread of nosocomial infections.

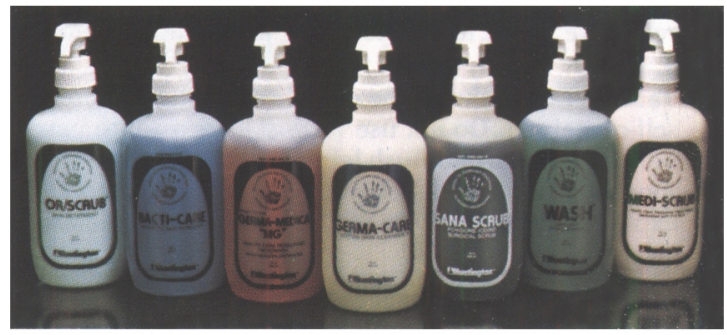

The latest addition to The Care System is Medi$S c r u b{ }^{\mathrm{TM}}$ our health care personnel handwash medi. cated with 0.6\% Para-Chloro-Meta-Xylenol.

It motivates people to wash more often. With a complete package of educational aids, and in-service training by your Huntington Representative.

If you'd like more information about the one and only complete handcare system, it's your turn to lift a finger. Just call Rosalee Sheets, collect, at (219) $356-8100$. 